\title{
Preliminary Report on Sugar Beets in Louisiana ${ }^{2}$
}

\author{
By C. E. Coates ${ }^{2}$ and A. F. Kidder ${ }^{3}$
}

Louistana State University, Baton Rovge, Louistana

A LONG series of results show that it is possible to grow sugar beets of high sucrose and high purity in Louisiana and to obtain heavy yields. This is probably true for the South in general. The best results are obtained by late spring planting. The yields average 18 tons per acre, the purities about 85.0, and the sucrose 14.0. The essential feature is the necessity for obtaining good seed which breeds true to type. Seed grown in the United States to-day fulfils this requirement.

$$
\text { ............ }
$$

The beet sugar industry is in many ways one of the romances of applied science. In 1747 Marggraff of Berlin found 6.2 per cent of sucrose in some beets he had examined. Forty years later Achard, also of Berlin, found that by careful selection of beets he was able to increase the average sugar content considerably, and he established a small factory in 1801, aided by a grant from the King of Prussia.

Since then, beets have been raised in sucrose content from 6 to an average of 15 per cent, occasionally running 18,20 , and even 30 per cent. This has been entirely due to scientific agriculture. From the standpoint of chemical engineering, on the other hand, the manufacturing process has been improved so that now there is a yield of from 250 to $300 \mathrm{lbs}$. of sugar per ton, together with several valuable by-products. This sugar is chemically pure, without flavor of any sort, and enters the markets of the world in free competition with any other type of sugar. Here then is an industry which bas been made possible by scientific agriculture and by applied chemistry working hand in hand, producing an agricultural crop worth hundreds of millions of dollars. There were produced in the United States alone in the year 1919 to $1920,726,000$ tons of beet sugar, which is more than the entire production of cane sugar of the United States with Hawaii thrown in. Not one pound of this would have been produced to-day under the conditions, chemical and agricultural, which existed a century ago. The industry is a magnificient monument to applied science.

\section{Semp Selection}

All this is well known, but it is necessary to repeat wellknown facts in order that one may not lose sight of their significance. In this case, first of all, the sugar content of beets was steadily increased by careful seed selection. The growing of sugar beets for seed is, in reality, a fine art and must be done under the most careful scientific control, but the details of the technic have been mastered and for the last three or four years good beet seed grown in America has been obtainable.

One of the writers (Coates) gave this matter considerable study about twenty-five years ago and in 1899 carried out a series of experiments at the Louisiana State University. It was evident that if beets could be matured in the spring they could be worked into sugar in Louisiana sugarhouses and thus extend the sugar season three months or more. One of the weak points in the Louisiana sugar industry is the fact that the expensive sugarhouses can run only about

1 Presented before the Division of Agricultural and Food Chemistry at the 62 nd Meeting of the American Chemical Society, New York, N. Y., September 6 to $10,1921$.

2 Dean, Audubon Sugar School.

${ }^{3}$ Agronomist and Assistant Director, Louisiana State Experiment Station, Baton Rouge, La. two months out of twelve. If three months could be added to this, their value would be almost doubled.

The first experiments were made by Coates and Glenk. A commercial variety of Vilmorin Improved was planted in November 1898, and harvested the following May and June (Table I). The results were encouraging, as many beets were found having 14.5 per cent sucrose and a purity of 90 . The difficulty was that other beets from the same row had grown so large that in them the sucrose had fallen to less than 9 per cent and the purity to about 70. A careful study of the situation convinced Coates that the beet seeds were not uniform in quality. Some of the beets weighed about 1.5 to $2 \mathrm{lbs}$. and looked like normal sugar beets, while others, harvested at the same time, were obviously of another variety, mostly mangels which weighed 6 or 8 lbs., or even more, and were low in sucrose. The following year similar experiments were run, from which similar inferences were drawn as to the quality of the seed. In November 1904, Coates made two more plantings, one of Vilmorin Improved, and the other of Klein Wanzleben (Table II). The seed labeled Klein

$$
\text { TABLE I }
$$

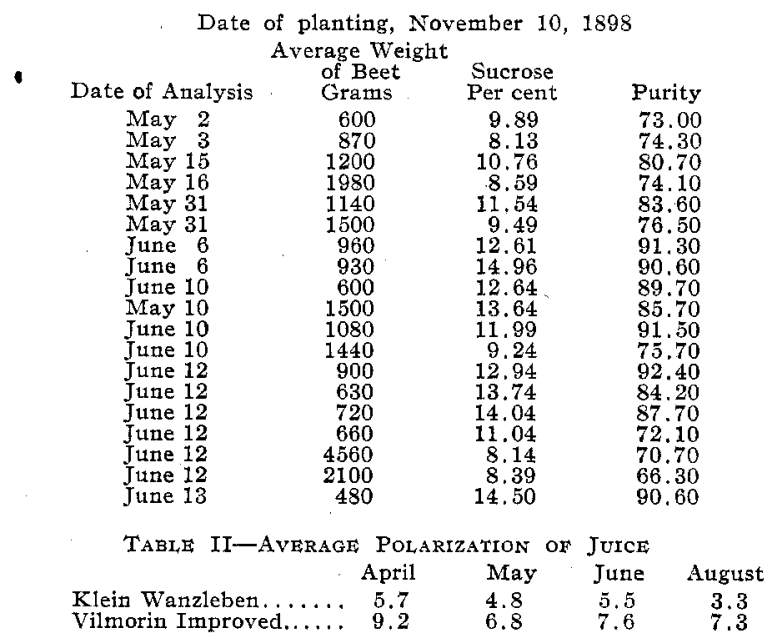

Wanzleben gave beets which were abnormally large and which were low in sucrose. The seed labeled Vilmorin did much better, but this too gave results which were disappointing. It was just possible that these seeds were intentionally mislabeled, as the beet sugar industry in the United States was threatening to be an important factor in the sugar world.

Two years later more plantings were made of Vilmorin and Klein Wanzleben, some November 26, 1907, some January 30, 1908, and a separate lot in August 1908 (Table III). The

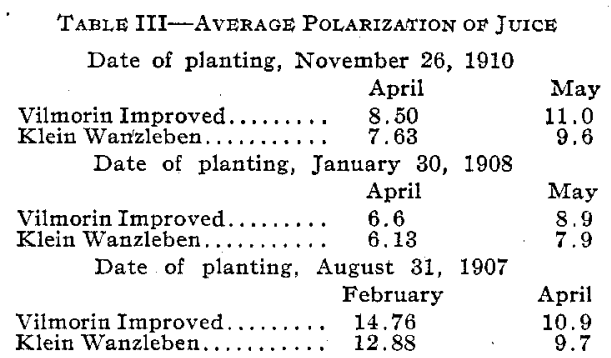

August seed gave fairly uniform results, high sucrose and 